\title{
General Theory of Relativity for Development Economics
}

\author{
Jiancheng Liu \\ Dongfang Boiler Co., Ltd., Zigong, China \\ Email: decljc@163.com
}

Received 7 March 2016; accepted 20 March 2016; published 24 March 2016

Copyright (C) 2016 by author and OALib.

This work is licensed under the Creative Commons Attribution International License (CC BY).

http://creativecommons.org/licenses/by/4.0/

(c) (i) Open Access

\section{Abstract}

This is a paper concerning the general national income, and on the basis of expounding the basic connotation of the scientific outlook on development, it discusses why the economic development is the central link in the development of human society; it puts forward the general formula of economic development from the equation of general national income, the matter growth equation, and the development speeds of China's economy, and clarifies the special formula of economic development from seven aspects as the economic growth pattern, the value of natural resources, the role of capital in economic growth, the contribution of the total factors to economic growth and so on; the paper analyzes the current situation of the economic development in America, Europe, Asia and Africa, and especially analyzes the situation of China; at last, the paper puts forward the enlightenment of China's economic development by using the general formula of economic development and the special formula of economic development.

\section{Keywords}

Scientific Outlook on Development, General National Income, Matter Growth Equation, Economic Growth Patterns

Subject Areas: Development Economics

\section{1. 引言}

自然界一切都是有生命的, 其产生、存在、发展、衰亡和再生等, 都遵循一定的规律, 都有一定的 生命周期, 自然本身也不例外。人及人类社会是自然发展到一定阶段的产物, 其产生、存在、发展、衰 亡和再生等, 也都遵循一定的规律, 都有一定的生命周期。正是由于自然、人及人类社会的这种特性, 才对自然、人及社会本身的和谐发展和它们之间的相互协调提出了特定的要求：人与自然、人与社会、 社会与自然及人类、社会和自然的各个个体之间必须相互尊重, 相互适应, 和平共处, 共同和谐发展。 
人与自然和谐发展, 是统治人类和自然的最高规律, 是指导人类社会实践的根本准则。将这一准则应用 于人类社会, 便提出了对社会和谐发展的基本要求。和谐发展的社会即科学的社会, 是实现共产主义的 必经阶段。经济发展是社会发展的中心任务, 是到达共产主义社会的根本途径。天时、地利、物运、人 和等四方面都影响着时间, 经济学意义上的时间是这四者的函数。除环境保护、地理位置、物体(包括人) 移动的速度以外, 经济发展与劳动力、资本(物化劳动)、科技进步和经济体制等密切相关。

本文是一篇关于广义国民收入的文章, 在详细阐述科学发展观的基本内涵的基础上, 论述了经济发 展是人类社会发展的中心环节; 从广义国民收入方程、事务成长方程以及中国的经济发展速度三个方面 提出了经济发展的广义公式, 并从经济增长方式、自然资源的价值、资本在经济增长中的作用、全要素 对经济增长的贡献等七个方面阐明了经济发展的狭义公式; 文章对美洲、欧洲、亚洲、非洲的经济发展 现状进行了分析评价, 并重点对中国的情况进行了分析; 最后结合文章提出的经济发展广义公式和狭义 公式, 提出了中国经济发展的启示。

\section{2. 科学发展观的主要内容和基本内涵[1]}

以人为本、全面协调可持续发展的科学发展观，是中国共产党从新世纪新阶段党和国家事业发展全 局出发提出的重大战略思想, 是我们推动经济社会发展、加快推进社会主义现代化必须长期坚持的重要 指导思想。

必须坚持以人为本，就是要以实现人的全面发展为目标，从人民群众的根本利益出发谋发展、促发 展, 不断满足人民群众日益增长的物质文化需要, 切实保障人民群众的经济、政治、文化权益, 让发展 成果惠及全体人民。

必须坚持全面发展，就是要以经济建设为中心，全面推进经济建设、政治建设、文化建设和社会建 设, 实现经济发展和社会全面进步。

必须坚持协调发展，就是要统筹城乡发展、统筹区域发展、统筹经济社会发展、统筹人与自然和谐 发展、统筹国内发展和对外开放，推进生产力和生产关系、经济基础和上层建筑相协调，推进经济建设、 政治建设、文化建设、社会建设和生态建设的各个环节、各个方面相协调。

必须坚持可持续发展，就是要促进人与自然的和谐，实现经济发展和人口、资源、环境相协调，坚 持走生产发展、生活富裕、生态良好的文明发展道路，保证一代接一代地永续发展。

必须坚持五大发展理念: 崇尚创新、注重协调、倡导绿色、厚植开放、推进共享。创新一一创新是 引领发展的第一动力; 协调一一协调发展、平衡发展、兼容发展; 绿色一一环境就是民生; 开放一一以 开放的最大优势谋求更大发展空间；共享一一决不让一个少数民族、一个地区掉队 [2] [3]。

科学发展观的第一要义是发展, 核心是以人为本, 基本要求是全面协调可持续发展。这三个方面相 互联系、有机统一, 其实质是实现经济社会又好又快发展。以人为本, 就是一切从人民群众的需要出发, 促进人的全面发展, 实现人民群众的根本利益。以人为本是科学发展观的核心和本质, 是我们一切工作 的出发点和归宿。

\section{3. 经济发展是人类社会发展的中心环节}

人们日益增长的物质文化需要同相对落后的社会生产之间的矛盾，始终是任何社会的主要矛盾，是 经济社会发展的根本动力。树立和落实科学发展观，必须始终把经济建设放在中心位置，聚精会神搞建 设, 一心一意谋发展。全国都要增强促进发展的紧迫感, 在任何时候任何情况下都紧紧扭住经济建设这 个中心不放松, 充分调动和切实保护广大干部群众加快发展的积极性, 坚定不移地推动经济持续快速协 调健康发展。 
马克思主义认为, 生产力的发展是人类社会发展的最终决定力量。社会主义现代化必须建立在发达 的生产力基础上。我国正处于并将长期处于社会主义初级阶段。社会主义初级阶段的主要矛盾, 始终是 人民日益增长的物质文化需要同落后的社会生产之间的矛盾, 解放和发展生产力始终是我们的中心任务。 党执政兴国的第一要务是发展, 首先是要发展经济。国家的昌盛, 人民的富裕, 说到底是经济实力问题。 国际竞争, 说到底也是经济实力的竞争。只有经济发展了, 经济实力和综合国力增强了, 人民的生活才 能不断改善, 国家才能长治久安, 促进人的全面发展才有坚实的物质基础, 我们才能在国际格局中占据 更加有利的地位。以经济建设为中心, 任何时候任何情况下都不能动摇、不能放松。

坚持以经济建设为中心, 必须以高度的责任感和紧迫感, 抓住机遇加快经济发展, 保持平稳较快的 经济发展势头。改革开放以来, 我国国内生产总值年均增长百分之九点四, 按当年平均汇率计算, 2015 年已经达到十万多亿美元, 稳居世界第二位, 占全球经济总量的比重约百分之二十, 人均八千多美元, 已属于中等收入国家。党的十八对全面建成小康社会进行了总体部署, 提出到 2020 年人均国内生产总值 要比 2010 年再翻一番。当今世界, 经济全球化趋势深入发展, 综合国力竞争日趋激烈。只有加快经济发 展, 才能确保实现全面建成小康社会的宏伟目标, 才能更好地解决前进道路上的矛盾和问题, 才能有效 应对各种风险和挑战。紧紧抓住和切实用好重要战略机遇期, 大力解放和发展社会生产力, 对于我国加 快实现现代化具有重大战略意义。

我们强调加快经济发展, 不是单纯追求国内生产总值(GDP)增长。国内生产总值是目前世界通用的重 要的宏观经济指标, 具有综合性强和简便易行的优点。但是, 国内生产总值不能全面反映经济增长的质 量和结构, 不能全面反映人们实际享有的社会福利水平。要以科学精神、科学态度和科学的思想方法看 待国内生产总值, 防止任何片面性和绝对化。要把加快经济发展, 建立在优化结构、提高质量和效益的 基础上。忽视增长的质量和效益, 不惜浪费资源和破坏环境, 片面追求一时的高速度, 势必会造成大的 起落, 就不能实现真正的发展。有质量、有效益的发展, 才是真正的发展, 才真正体现了发展的硬道理。

\section{4. 经济发展速度的广义公式}

\section{1. 广义国民收入}

天时、地利、物运、人和等四方面都影响着国民收入的质量, 广义上的国民收入 $y_{G}$ 是这四者和狭义 国民收入 $y_{s}$ (即我们常说的国民经济收入 $y$ ) 的函数。所谓广义国民收入, 就是考虑了环境保护、物体运 动速度和社会人际关系和谐等的影响而进行修正后的国民收入。广义国民收入和狭义国民收入的关系如 下:

$$
y_{G}=y_{S} f(w, e, v, h)=y f(w, e, v, h)
$$

式中 $(w=$ 天时 $)+(e=$ 地利 $)=$ 环保 $(e p)$ 。

$f(e p)=$ 环保系数, 且 $-\infty \leq f(e p) \leq 1$ 。

$f(v)=$ 物运系数, 且 $f(v)=k \frac{v_{n}}{v_{n-1}}, 0 \leq k \leq 1$ 。

$v_{n}=$ 人及物体当前的平均移动速度; $v_{n-1}=$ 人及物体前期的平均移动速度。

$f(h)=$ 人和系数, 且 $-\infty \leq f(h) \leq k_{h}, k_{h} \geq 1$ 。

所以, $y_{G}=y f(e p) f(v) f(h)$

$$
\frac{\mathrm{d} y_{G}}{y_{G}}=\frac{\mathrm{d} y}{y}+\frac{\mathrm{d} f(e p)}{f(e p)}+\frac{\mathrm{d} f(v)}{f(v)}+\frac{\mathrm{d} f(h)}{f(h)}
$$


即广义国民收入的增长率 $\frac{\mathrm{d} y_{G}}{y_{G}}$ (即广义经济发展速度)等于国民经济收入的增长率 $\frac{\mathrm{d} y}{y}$ (狭义经济发展速度) 与环保系数的变化率 $\frac{\mathrm{d} f(e p)}{f(e p)}$ 、物运系数的变化率 $\frac{\mathrm{d} f(v)}{f(v)}$ 以及人和系数的变化率 $\frac{\mathrm{d} f(h)}{f(h)}$ 四者之和。

对(1)式进行分析可以得出三点结论:

1) 环保问题是影响广义经济发展速度的关键要素, 最糟糕的情况为 $-\infty$, 将致使人类毁灭; 最好的 情况为 1 , 使人类经济持续、健康、稳定发展。

2) 物运速度是制约广义经济发展的最重要因素。由分析可知: (1)行政区划面积应相对集中。交通越 便利的地方, 区划面积可以大些; 交通不便利的地方, 区划面积应小些。(2)地域狭长的国家或地区发展 经济将非常困难; 面积小而集中的国家或地区由于发展容易而相对发达。(3)国家及行政区划之间的边界 最好为直线, 以尽量缩短交通时间, 从而促进经济发展。(4)交通和通讯已成为一个国家或地区经济发展 速度快慢的决定性因素。

3) 人和问题也是影响广义经济发展的一个重要因素。人口过少, 劳动力短缺, 不利于经济发展; 而 人口过多, 劳动力过剩, 也不便发展。所以必须控制人口增长或过度减少, 改善人口结构, 提高人口素 质, 并大力发展科技, 促使技术进步, 最大限度地提高生产力水平。此外人类应该尽最大努力避免战争, 以保证人和系数为正, 并尽可能使其大于 1 。

\section{2. 事物成长方程}

宇宙万物一旦出生, 都应随时间一起成长, 所以有:

$$
\frac{\mathrm{d} q}{q}=\lambda \frac{\mathrm{d} t}{t}
$$

式中 $q$ 为宇宙万物(包括人类)的规模(大小)和质量(品质), $t$ 为时间, $\lambda$ 为系数。由于对任何事物都可 以仅用质量(品质)和规模(大小)两个参数加以描述, 所以, 如果设某种事物诞生时的质量(品质)或规模(大 小)为 1 , 孕育时间为 $t_{0}$, 那么, 对(2)式积分, 有:

$$
\int_{1}^{q} \frac{\mathrm{d} q}{q}=\int_{t_{0}}^{t} \lambda \frac{\mathrm{d} t}{t}
$$

由此得到事物质量(品质)或规模(大小)成长方程如下:

$$
\ln q=\lambda\left(\ln t-\ln t_{0}\right)
$$

如果 $\lambda=1$

$$
\ln q=\ln t-\ln t_{0}
$$

表明事物质量(品质)或规模(大小)发展与时间同步, 称为同步发展。

如果 $0<\lambda<1$

$$
\ln q<\ln t-\ln t_{0}
$$

表明事物质量(品质)或规模(大小)发展落后于时间的步伐, 称为滞后发展。

如果 $\lambda>1$

$$
\ln q>\ln t-\ln t_{0}
$$

表明事物质量(品质)或规模(大小)发展领先于时间, 称为领先发展。 
如果 $\lambda<0$, 事物质量(品质)或规模(大小)将会出现衰退。

引入事物势(记为 $P$ ) 的概念, 它被定义为某一事物的数量 $(Q)$ 与该事物的质量水平 $(q)$ 的乘积, 那么 有:

$$
\begin{gathered}
P=Q \cdot q \\
\frac{\mathrm{d} P}{P}=\frac{\mathrm{d} Q}{Q}+\frac{\mathrm{d} q}{q}
\end{gathered}
$$

即事物势的增长率 $\frac{\mathrm{d} P}{P}$ 等于事物数量的增长率 $\frac{\mathrm{d} Q}{Q}$ 和该事物质量水平的增长率 $\frac{\mathrm{d} q}{q}$ 之和。

\section{3. 中国经济的发展速度}

\section{(1) 对过去数据的分析}

由于

$$
\frac{\mathrm{d} y}{y}=\frac{\mathrm{d} Q}{Q}+\frac{\mathrm{d} q}{q}
$$

式中, $y=$ 剔除了价格变动的实际产出或收入。

$Q=$ 产品产量。

$q=$ 产品平均质量水平。

即国民收入增长率(实际值) $\frac{\mathrm{d} y}{y}$ 等于产品产量增长率 $\frac{\mathrm{d} Q}{Q}$ 和产品平均质量水平增长率 $\frac{\mathrm{d} q}{q}$ 之和。

\section{a) 孕育期从文革结束开始算起}

假设从 1978 年底开始, 中国经济发展才走上正轨, 并与时间同步发展。设发展前的孕育期为 1 年, 那么由公式(4), 有

$\ln y=\ln t-\ln t_{0}=\ln 37-\ln 1=3.61$

$y=\mathrm{e}^{3.61}=37$ 倍。

而实际上, 到 2015 年底这 37 年中, 我国的实际 GDP(由于 GDP 与 GNI 相差不大, 可认为 $y=\mathrm{GNI}=\mathrm{GDP}$ ) 只增长为 1978 年的 31.55 倍, 似乎没有做到同步发展, 更不用说领先发展了, 而只是一 种滞后发展。

如果将 1976 年 10 月粉碎 “四人帮” 至 1978 年底十一届三中全会召开之间的两年零两个月(2.167 年) 作为孕育期, 则同步发展的 $q$ 为:

$\ln y=\ln t-\ln t_{0}=\ln 39.167-\ln 2.167=2.895$

$y=\mathrm{e}^{2.895}=18.06$ 倍 $<31.55$ 倍。

这样一来, 便可以认为我国经济发展为领先发展。那么当 $y=31.55$ 倍时, 相当于同步发展到了哪一 年了?

$\ln t=\ln y+\ln t_{0}=\ln 31.55+\ln 2.167=4.225$

$t=\mathrm{e}^{4.225}=68.37$ 年, 即发展程度提前了 31.4 年左右, 已发展到 2046 年。我国经济实际发展速度是 同步发展速度的 $\frac{68.37}{37}=1.848$ 倍。

那么从 1977 年至 2015 年, 我国的产品产量发展速度如何呢?

以粮食生产为例, 1977 年我国粮食总产量为 3000 亿公斤, 而 2015 年为 6214 亿公斤, 即增长了 $107.1 \%$, 年均增长 $1.98 \%$ 。 
由于钢铁、水泥、煤炭、电力等在 37 年间增加了较多, 不妨认为这 37 年间我国产品产量增加了 7 倍(准确数据应国家统计局提供), 即年均增加 $5.4 \%$ 。那么, 可以计算出我国 2015 年的产品平均质量水平 提高为 1977 年的 4.507 倍, 即年均提高 4.15\%。我国产品平均质量的发展速度如何呢?

同前, 仍假设从 1978 年底开始, 中国经济发展才走上正轨, 产品质量水平与时间同步发展。设发展 前的孕育期仍为两年零两个月(2.167 年), 那么由公式(4), 有

$\ln q=\ln t-\ln t_{0}=\ln 39.167-\ln 2.167=2.895$

$q=\mathrm{e}^{2.895}=18.06$ 倍。

即年均提高 $8.1 \%$ 。

而实际为年均提高 $4.15 \%$, 该发展速度仅为同步发展速度的一半。那么, 如果我国产品平均质量水 平为同步发展, 目前的水平相当于发展到哪一年了呢?

由公式(4), 我们有

$\ln t=\ln q+\ln t_{0}=\ln 4.507+\ln 2.167=2.279$

$t=\mathrm{e}^{2.279}=9.77$

即目前的实际产品平均质量水平只相当于发展到了 1986 年。

\section{b) 孕育期从中华人民共和国成立开始算起}

假设从 1949 年 10 月 1 日中华人民共和国成立之日起, 我国经济开始孕育, 而直到 1978 年底开始, 中国经济发展才走上正轨, 并与时间同步发展。那么我国经济的孕育期为 29 年, 那么由公式(4), 有

$\ln y=\ln t-\ln t_{0}=\ln 67-\ln 29=0.837$

$y=\mathrm{e}^{0.837}=2.31$ 倍。

即年均增长 $2.29 \%$ 。

而实际上, 到 2015 年底这 37 年中, 我国的实际 GDP 增长为 1978 年的 31.55 倍, 实现了大幅度的 领先发展。

那么从 1977 年至 2015 年, 我国的产品产量发展速度如何呢?

以粮食生产为例, 1977 年我国粮食总产量为 3000 亿公斤, 而 2015 年为 6214 亿公斤, 即增长了 $107.1 \%$, 年均增长 $1.98 \%$, 没能实现同发展, 而是一种滞后发展。

但是, 由于钢铁、水泥、煤炭、电力等在 37 年间增加了较多, 不妨认为这 37 年间我国产品产量增 加了 7 倍(准确数据应国家统计局提供), 即年均增加 5.4\%, 也实现了大幅度的领先发展。同时, 可以计 算出我国 2015 年的产品平均质量水平提高为 1977 年的 4.507 倍, 即年均提高 $4.15 \%$, 我国产品平均质量 水平同样实现了较大幅度的领先发展。

对上述分析进行比较, 可以发现, 事物(包括一个国家的经济水平)的孕育期越长, 其出生后的发展速 度越慢; 孕育期越短, 其出生后的发展速度越快。在事物出生以后, 其初期发展(成长)速度较快, 而随着 时间的推移, 其发展(成长)速度会越来越慢, 最后将趋近于 0 。即新生事物发展(成长)快, 旧事物发展(成 长)慢, 所以要鼓励新生事物的诞生和发展, 并对旧事物进行改造, 促其新生。改革开放即是促进了国家 的新生。对经济水平而言, 新兴国家的发展速度将会明显高于发达国家。

\section{(2) 对 2016 年数据的要求}

假设我国经济仍保持这 37 年来的平均发展速度, 那么有

$$
\frac{\mathrm{d} y}{y_{2015}}=\frac{\mathrm{d} Q}{\mathrm{~d} Q_{2015}}+\frac{\mathrm{d} q}{\mathrm{~d} q_{2015}}=5.4 \%+4.15 \%=9.55 \%
$$

即只要 2016 年我国 GDP 实际增长 9.55\%, 就延续了这 37 年来的良好发展趋势。但是, 由于国际经济、 
金融危机的影响, 我国经济的发展速度应适当调低, 比如 7\%。同时, 由于国际经济危机对我国产品出口 的严重影响, 我们应适当调低产品产量的增速, 比如从 $5.4 \%$ 调低为 $2 \%$, 而适当调高产品平均质量水平 的提高率, 比如从 $4.15 \%$ 调高为 $6 \%$, 从而保证实际 GDP7-8\%的增速。

\section{(3) 今后的发展趋势}

由于事物成长方程的特性, 随着时间的推移, 其成长(发展)速度呈现先快后慢的属性, 当时间无限长 时, 发展速度趋近于 0 。对于我国经济发展来说, 我们只能采取领先发展的策略, 即在提高产品质量、 开发新产品和培养新产业等方面下功夫, 提高经济发展的速度。

\section{5. 经济发展速度的狭义公式}

除环境保护、地理位置、物体(包括人)移动的速度以外, 经济发展与劳动、资本(物化劳动)、技术进 步、制度安排、结构变化以及劳动者素质和技能的提高等密切相关。公式如下:

\section{1. 劳动和劳动生产率分析}

产出 $y$ 的大小主要取决于劳动投入量的大小 $(L)$ 和劳动生产率 $\left(\frac{y}{L}\right)$ 的高低[4]-[6]。因此, 产出水平等 于劳动力总数与平均劳动生产率之积:

$$
\begin{aligned}
& y_{t}=\left(\frac{y}{L}\right)_{t} \cdot L_{t} \\
& \frac{\mathrm{d} y}{y}=\frac{\mathrm{d}(y / L)}{y / L}+\frac{\mathrm{d} L}{L}
\end{aligned}
$$

引入人口变量 $P$, 则有

$$
\begin{aligned}
& \frac{y}{P_{t}}=\frac{1}{P_{t}} \cdot\left(\frac{y}{L}\right)_{t} \cdot L_{t} \\
& \frac{\mathrm{d}(y / P)}{y / P}=\frac{\mathrm{d}(y / L)}{y / L}+\frac{\mathrm{d} L}{L}-\frac{\mathrm{d} P}{P}
\end{aligned}
$$

式中, $\frac{\mathrm{d}(y / L)}{y / L}$ 项可以理解为由于技术进步(资本有机构成改变)、制度安排、结构变化及劳动者素质 和技能等对全员劳动平均产出的贡献, 可正、可负; $\frac{\mathrm{d} L}{L}$ 为投入劳动的增量对全员劳动平均产出的直接贡 献, 亦可正、可负; $\frac{\mathrm{d} P}{P}$ 为人口变化对全员劳动平均产出的影响, 人口增加时, 全员劳动平均产出降低, 人口减少时, 全员劳动平均产出增高。从公式可以看出, 要使全员劳动平均产出增加, 就必须重视技术 进步(改善资本有机构成), 改进制度安排和结构, 提高劳动者的素质和技能, 以保证 $\frac{\mathrm{d}(y / L)}{y / L}$ 项为正; 同 时, 要确保投入劳动的增量 $\frac{\mathrm{d} L}{L}$ 大于人口增量 $\frac{\mathrm{d} P}{P}$ 。

\section{2. 自然资源的价值}

人类首先是自然的产物, 他对自然的影响是有限的, 是自然决定了人类的生存和发展, 而不是相反。 因此科学合理的经济学尘须考虑自然资源的稀缺性。

经济学的研究对象是物品的稀缺性与人们有目的的选择之间, 既人与物之间的关系。物品的稀缺性 
是人类社会的一个永恒性问题。因为人类社会要靠物质资料才能生存和发展。这些物质资料可以分为 “自 由取用物品” (即自然中原来就存在, 不必付出任何代价即可得到的物品, 如空气、阳光等等)和 “经济物 品” (即需要利用自然界存在的各种资源, 通过人的劳动而生产出来的产品)。前者是无限的, 而后者却是 有限的。这样，一方面人类对 “经济物品” 的欲望是无限的，而另一方面用以满足人类欲望的 “经济物 品” 又是有限的。因而相对于人类社会的无穷欲望而言, 经济物品和生产这些物品所需要的资源就总是 不足的, 这就是经济物品和生产这些物品所需要的资源的稀缺性。这种稀缺的相对性存在于人类社会的 一切时期。

实际上, 自然界的一切资源都是有价值的, 它们的价值等于由完全人工合成手段获得该资源所需付 出的全部人类劳动的当期价值。所以, 越是用人工手段难以合成的物品, 其价值越高。自然界一切产物 在人类对其进行加工以前, 皆属于自然本身的贡献: 空气由地球贡献, 阳光由太阳贡献, 水由大海贡献, 雨露由阳光、大气和海洋组成的系统贡献。自然界的一切资源, 包括空气、阳光和水, 都是相对无限, 而绝对有限的。因此, 我们必须珍惜自然, 尊重自然, 热爱自然, 合理利用自然。

\section{3. 资本在经济增长中的作用}

资本是人类经济活动的基本要素之一。古典和新古典经济增长理论中, 资本对经济增长的作用被提 到极其重要的高度, 经济增长被认为主要是积累足够的资本, 从而可以运用劳动和资本在经济上最有效 的组合所获得的结果, 进而通过深化资本结构和提高资本密集度的方式来促进经济的增长。

（1）四部门经济中国民收入的决定[7]-[9]

四部门经济中均衡收入为:

$$
y=\frac{1}{1-\beta(1-t)+\gamma}\left(a+\bar{i}+\bar{g}-\beta T_{0}+\beta T_{R}+\bar{x}-m_{0}\right)
$$

式中

$y=$ 剔除了价格变动的实际产出或收入;

$\beta=$ 边际消费倾向;

$t=$ 边际税率;

$\gamma=$ 边际进口倾向;

$a=$ 必不可少的自发消费部分, 即收入为 0 时举债或运用过去的储蓄也必须要有的基本生活消费;

$\bar{i}=$ 经济均衡时的投资;

$\bar{g}=$ 经济均衡时的政府购买;

$T_{0}=$ 税收常数, 为定额税;

$T_{R}=$ 政府转移支付;

$\bar{X}=$ 经济均衡时的出口额;

$m_{0}=$ 自发性进口, 即和收入没有关系或者说不取决于收入的进口部分, 例如本国不能生产, 但又 为国计民生所必需的产品, 不管收入水平如何, 是必须进口的。

(2) 四部门经济中的乘数

由上述四部门经济中均衡收入决定的公式可以得到:

$$
\begin{aligned}
\frac{\mathrm{d} y}{\mathrm{~d} a} & =\frac{\mathrm{d} y}{\mathrm{~d} \bar{i}}=\frac{\mathrm{d} y}{\mathrm{~d} \bar{g}}=\frac{\mathrm{d} y}{\mathrm{~d} \bar{x}}=\frac{1}{1-\beta(1-t)+\gamma} \\
\frac{\mathrm{d} y}{\mathrm{~d} T_{0}} & =\frac{-\beta}{1-\beta(1-t)+\gamma}
\end{aligned}
$$




$$
\begin{aligned}
\frac{\mathrm{d} y}{\mathrm{~d} T_{R}} & =\frac{\beta}{1-\beta(1-t)+\gamma} \\
\frac{\mathrm{d} y}{\mathrm{~d} m_{0}} & =\frac{-1}{1-\beta(1-t)+\gamma}
\end{aligned}
$$

由于 $1>t>0$ 以及 $1>\gamma>0$, 因此, $\frac{1}{1-\beta}>\frac{1}{1-\beta(1-t)}>\frac{1}{1-\beta(1-t)+\gamma}$ 。可见, 由于税收和进口, 自 发消费、投资、政府购买和出口的乘数减小了, 当 $\gamma-\beta(1-t)>0$ 时, 它们的乘数小于 1 , 将会出现欠增 长。所以, 必须对边际进口倾向进行严格控制, 鼓励进口替代, 使 $\gamma<\beta(1-t)$ 。当 $\frac{1}{1-\beta(1-t)+\gamma}>1$ 时, 自发消费、投资、政府购买和出口的增加均能使收入超增加, 而定额税和自发性进口的增加, 会使收入 减少。当 $\frac{\beta}{1-\beta(1-t)+\gamma}>1$ 时, 转移支付的增加也会使收入超增加。边际消费倾向 $\beta$ 越高, 乘数越大, 收入增加越多, 所以应鼓励合理消费, 扩大内需。

(3) 资本对经济增长的贡献

从广义上讲，投资、政府购买和转移支付均可被视为资本投入，所以由(12)式可以得出:

$$
\Delta y=\frac{1}{1-\beta(1-t)+\gamma}\left(\Delta i+\Delta g+\beta \Delta T_{R}\right)
$$

显然, 必须使 $\gamma<\beta(1-t)$, 否则, 资本投入的增加不能带来收入的超增长。

\section{4. 全要素生产率对经济增长的贡献}

$$
\Delta y=\frac{1}{1-\beta(1-t)+\gamma}\left(\Delta a+\Delta i+\Delta g-\beta \Delta T_{0}+\beta \Delta T_{R}+\Delta x-\Delta m_{0}\right)
$$

该公式可以说对经济发展与劳动、资本(物化劳动)、技术进步、制度安排和结构变化等的关系均进行 了考虑。

\section{5. 资本 (物化劳动) 为什么会增值?}

马克思说过, 劳动, 只有劳动, 才是创造社会财富的唯一源泉。那么, 为什么资本会增值呢? 我们 都知道, 根据马克思的劳动价值学说, 任何商品的价值都是由创造该商品的社会必要劳动时间决定的, 而资本是对社会必要劳动时间的货币度量, 是与当期的社会必要劳动量对应的。随着时间的推移, 当技 术进步、制度安排和结构发生改善、劳动者素质和技能提高时, 生产商品的社会必要劳动时间会缩短, 那么与原来的社会必要劳动时间对应的劳动量可以创造出更多的社会财富, 与资本对应的原社会必要劳 动的量也可以对应更多的社会财富, 资本便增值了。

5.6. 对乘数 $\alpha=\frac{1}{1-\beta(1-t)+\gamma}$ 的分析

(1) $\gamma$ 对 $\alpha$ 的影响

由于 $1>t>0$, 有 $1-t>0$, 而 $\beta \geq 0$, 所以 $\beta(1-t) \geq 0$ 。而一般情况下, $\gamma \geq 0, \beta(1-t) \leq 1$, 此时, $\gamma$ 越小, 乘数 $\alpha$ 越大, $\gamma$ 越大, 乘数 $\alpha$ 越小; 当 $\gamma \geq \beta(1-t)$ 时, 有 $\alpha \leq 1$, 从(13)式可以看出, 自发消费、 投资、政府购买和出口增长的乘数小于 1 , 将会出现欠增长, 即没有效率的增长。所以, 正常情况下, 必须对边际进口倾向进行严格控制, 鼓励进口替代, 使 $\gamma<\beta(1-t)$ 。 
(2) $t$ 对 $\alpha$ 的影响

正常情况下, $\beta(1-t) \leq 1, \gamma \geq 0$, 此时, $t$ 越小, 乘数 $\alpha$ 越大, $t$ 越大, 乘数 $\alpha$ 越小。所以, 国家 应制定合理的税率, 过高的税率会抑制经济的增长速度, 当税率高到使 $\gamma \geq \beta(1-t)$ 时, 自发消费、投资、 政府购买和出口增长的乘数将小于 1 , 则会出现欠增长, 即没有效率的增长。所以, 国家的税率 应根据公式 $t<1-\frac{\gamma}{\beta}$ 的要求进行调整。在目前情况下, $\gamma=0.4, \quad \beta=0.6$, 所以 $t<1-\frac{0.4}{0.6}=33.3 \%$; 而 实际的 $t=20 \% \leq 33.3 \%$, 基本是合理的。但是, 我国的税收结构存在较多不合理的情况, 比如个人所得 税、劳动密集型中小企业的税收、消费税(特别奢侈品消费税)和上市公司红利税等, 都存在一些不合理的 地方。

(3) $\beta$ 对 $\alpha$ 的影响

正常情况下, $\beta(1-t) \leq 1$, 但也有特殊的情况, 使 $\beta(1-t)>1$, 即 $\beta>\frac{1}{1-t}>1$, 此时, $t<1-\frac{\gamma}{\beta}$ 的 条件自然满足, 所以对税率 $t$ 没有特殊的要求。但是, 由于此时 $1-\beta(1-t)<0$, 要使 $\alpha>0$, 则必须有 $\gamma>\beta(1-t)-1$, 否则, $\alpha<0$, 自发消费、投资、政府购买和出口将会出现负增长, 即经济恶性衰退。 当 $\gamma-[\beta(1-t)-1]$ 的值正得越少, 经济将增长越快, $\gamma-[\beta(1-t)-1]$ 的值正得越多, 经济将增长越慢; 当 $\gamma-[\beta(1-t)-1]$ 的值负得越少, 经济将衰退越快, $\gamma-[\beta(1-t)-1]$ 的值负得越多, 经济将衰退越慢; 当 $\gamma-[\beta(1-t)-1]$ 的值接近于 0 时, 经济要么高速增长, 要么快速衰退。可以说, 在这种情况下, 一 个国家或地区的经济是在尖锐的刀锋上跳舞, 具有极端的不确定性。实际上, 美国经济某些时候就处于 这种情况下, 这也是美国经济增长长期不稳定的根源。同时, 这也就解释了为什么美国储蓄为负、大外 贸逆差长期存在而经济仍能增长的根本原因。

当然, 也可以在 $\beta>1$ 的情况下, 使 $\beta(1-t) \leq 1$, 即采取 $t \geq 1-\frac{1}{\beta}$ 的税收政策, 使 $1-\beta(1-t) \geq 0$ 。此 时, 前述 $\gamma$ 、 $t$ 对 $\alpha$ 影响的分析仍然成立。所以, 如果控制得好, 也可以在 $\beta>1 、 \beta(1-t) \leq 1$ 的情况下, 实现经济的高速增长, 美国经济发展好的时期就是这种情况。此时, 税率 $t$ 应满足 $1-\frac{1}{\beta} \leq t<1-\frac{\gamma}{\beta}$ 的条件。

\section{7. 经济增长方式}

(1) 产品质量与产出

从微观层面看, 全社会产出(即国民收入)的名义值 $y^{\prime}$ 的大小主要取决于全社会产品总产量的大小 $(Q)$ 和产品平均质量水平 $(q)$ 及产品平均价格水平 $\left(P_{0}\right)$ 的高低。因此, 全社会产出(国民收入)的名义值等于全 社会产品总产量与产品平均质量水平和产品平均价格水平三者的积:

$$
\begin{gathered}
y^{\prime}=Q \cdot q \cdot P_{0} \\
\frac{\mathrm{d} y^{\prime}}{y^{\prime}}=\frac{\mathrm{d} Q}{Q}+\frac{\mathrm{d} q}{q}+\frac{\mathrm{d} P_{0}}{P_{0}}
\end{gathered}
$$

式中, $\frac{\mathrm{d} Q}{Q}$ 为产品产量的增长率, $\frac{\mathrm{d} q}{q}$ 为产品平均质量水平增长率, $\frac{\mathrm{d} P_{0}}{P_{0}}$ 为产品平均价格水平增长率 (即通货膨胀率), 国民收入名义增长率 $\frac{\mathrm{d} y^{\prime}}{y^{\prime}}$ 等于这三者之和。而 


$$
\frac{\mathrm{d} y}{y}=\frac{\mathrm{d} y^{\prime}}{y^{\prime}}-\frac{\mathrm{d} P_{0}}{P_{0}}=\frac{\mathrm{d} Q}{Q}+\frac{\mathrm{d} q}{q}
$$

即国民收入增长率(实际值) $\frac{\mathrm{d} y}{y}$ 等于产品产量增长率 $\frac{\mathrm{d} Q}{Q}$ 和产品平均质量水平增长率 $\frac{\mathrm{d} q}{q}$ 之和。

提高产品平均质量水平，会成正比地增加国民收，大大促进经济增长。

(2) 经济增长方式

实际上, 我们可以称产品产量增长率为经济增长率的外延部分, 而称产品平均质量水平增长率为经 济增长率的内涵部分; 通过扩大产量获得的增长为外延式增长, 通过提高质量水平获得的增长为内涵式 增长, 两种方式皆用而获得的增长为复合式增长。外延式增长是不可能长期持续的, 当产品饱和或过剩 时, 其增长率为零或为负。这时, 我们必须将增长方式转变为内涵式增长, 即在提高产品质量上下功夫。 这是我国目前和今后较长一个时期所面临的真实情况。

(3) 劳动生产率的增长

由式(10)和(21)可得

$$
\frac{\mathrm{d}(y / L)}{y / L}=\frac{\mathrm{d} q}{q}+\frac{\mathrm{d} Q}{Q}-\frac{\mathrm{d} L}{L}=\frac{\mathrm{d} q}{q}+\frac{\mathrm{d}(Q / L)}{Q / L}
$$

即劳动生产率的增长率等于质量水平增长率与人均产品产量 $\frac{Q}{L}$ 的增长率之和。所以, 要提高劳动生 产率，就必须不断提高产品质量水平和人均产品产量。

同样, 我们可以称人均产品产量增长率为劳动生产率增长率的外延部分, 而称产品平均质量水平增 长率为劳动生产率增长率的内涵部分; 通过提高人均产品产量获得的增长为外延式增长, 通过提高质量 水平获得的增长为内涵式增长, 两种方式皆用而获得的增长为复合式增长。外延式增长是不可能长期持 续的, 当人均产品产量达到极限时, 其增长率为零或为负。这时, 我们必须将增长方式转变为内涵式增 长, 即在提高产品质量上下功夫。这也是我国目前和今后较长一个时期所面临的真实情况。

\section{6. 实例分析}

\section{1. 对整个世界的分析}

首先就美洲的情况进行分析。北美的加拿大和美国环保问题解决得相当好, 长期致力于科技进步, 交通发达, 历史上又长期没有经历战争或动乱, 特别是经济制度比较优越, 所以经济发展相对容易, 发 展速度较快, 早已成为发达国家。而墨西哥和中美洲国家则不具备上述优势, 所以发展较缓慢, 但中美 洲国家由于面积小而集中, 除个别因内战而政局不稳的国家外, 经济相对较发达。南美的巴西尽管自然 环境良好且资源丰富, 但由于地域不规则, 以及科技发展落后等, 因而经济发展较慢。智利和阿根廷虽 然环境良好、自然资源较丰富, 但由于南北狭长及科技发展落后, 故而经济发展迟缓。

其次对亚太地区的情况进行分析。俄罗斯尽管自然环境良好、资源丰富, 但由于其首都位于几乎最 西边的欧洲境内, 人口也多集中在这一带, 对经济发展相当不利, 再加经历了第二次世界大战和上世纪 90 年代的政治剧变, 特别是前苏联的计划经济制度的弊端, 其经济发展相当不稳定, 甚至出现了倒退。 至于东北亚的韩国和日本, 由于面积小而集中, 科技相对发达, 经济制度昌明, 因而经济发展曾一度遥 遥领先于世界绝大多数国家。东南亚的越南属于典型的南北狭长国家, 并受经济体制的制约, 经济发展 一度 相当困难。新加坡由于面积小而集中, 科技发达, 政治稳定, 经济制度良好, 同时又是世界航运和 航空中心, 故而发展速度较快。位于南半球的澳大利亚, 环境保护较好, 自然资源丰富, 历史上长期没 有经历过战争或动乱, 且经济制度较好, 故而经济发展较快。 
再对欧洲进行分析。所有欧洲国家面积较小而且集中, 环境优美, 人均资源丰厚, 除东欧国家外, 政治稳定, 科技发达, 经济制度昌明, 所以经济都比较发达。特别是北欧四国, 更是得天独厚。

最后对非洲进行分析。北非国家由于位处沙漠地带, 自然环境比较恶劣, 水资源匮乏, 且经济体制 相对落后, 故而经济发展都比较落后。赤道附近的非洲国家, 尽管自然环境较好, 资源相对丰富, 但由 于科技发展落后, 政治不稳定, 经济体制落后等, 故而发展也相当困难。至于南非, 由于自然资源丰富、 科技较发达、经济体制良好等原因，因而相对比较发达。

\section{2. 对中国情况的分析}

解放前的中国, 政局不稳, 制度(特别是经济制度)落后, 某些地区环境破坏严重, 战乱持续不断, 内 忧外患, 人口数量不稳定、人口素质差, 科技落后, 交通、通讯不发达, 故长期以来发展落后。解放后 至改革开放前, 政治运动频繁, 体制(特别是经济体制)落后, 环境破坏严重, 内乱不断, 人口数量过多、 人口素质差, 科技落后, 交通、通讯依然落后, 经济社会发展止步不前, 国民经济一度濒临崩溃。改革 开放 35 年来, 政治昌明, 时局比较稳定, 对体制(特别是经济体制)的改革不断推进并取得进步, 控制了 过快增长的人口数量, 大力发展交通、通讯, 大力推进教育事业、提高人口素质, 大力发展科技, 虽然 付出了一定的环境代价, 但经济社会持续快速发展, 取得了举世瞩目的成就。

当然, 由于地理、交通、教育、人口等因素的差别, 中国的经济发达程度由东向西呈递减趋势。东 部的北京、上海、辽宁、山东、江苏、浙江等, 较中部的河南、湖北、湖南等更发达; 而中部的这些省 份又较西部的陕西、甘肃、四川、云南等更发达。南北狭长的省份, 如陕西、甘肃, 其发展相对困难。 面积小而集中的省份, 如浙江、江苏、宁夏等, 又较同一地区面积大而分散的省份, 如山东、安徽、甘 肃等更发达。深圳、香港、澳门等地区, 由于面积小而集中并且高度自治而发展迅速。

\section{7. 公式对我国经济发展的启示意义}

\section{1.广义公式的启示意义}

第一, 环保问题是影响广义经济发展速度的关键要素, 最糟糕的情况将致使人类毁灭; 最好的情况 为 1 , 使人类经济持续、健康、稳定发展。所以, 国家应加强对环境的治理, 改善环境管理体制, 加大 环境治理投入, 建设良好的社会主义生态文明, 为经济社会建设保驾护航。第二, 物运速度是制约广义 经济发展的最重要因素, 所以, 行政区划面积应相对集中, 交通越便利的地方, 区划面积可以大些; 交 通不便利的地方, 区划面积应小些; 国家及行政区划之间的边界最好为直线, 以尽量缩短交通时间, 从 而促进经济发展; 交通和通讯已成为一个国家或地区经济发展速度快慢的决定性因素, 要大力发展交通 和通讯工业。第三, 人和问题也是影响广义经济发展的一个重要因素, 人口过少, 劳动力短缺, 不利于 经济发展; 而人口过多, 劳动力过剩, 也不便发展。所以必须控制人口增长或过度减少, 改善人口结构, 提高人口素质, 并大力发展科技, 促使技术进步, 最大限度地提高生产力水平。此外人类应该尽最大努 力避免战争, 以保证人和系数为正, 并尽可能使其大于 1 。第四, 新生事物发展(成长)快, 旧事物发展(成 长)慢, 所以要鼓励新生事物的诞生和发展, 并对旧事物进行改造, 促其新生。改革开放即是促进了国家 的新生。对经济水平而言, 新兴国家的发展速度将会明显高于发达国家。对于我国经济发展来说, 我们 只能采取领先发展的策略, 即在提高产品质量、开发新产品和培养新产业等方面下功夫, 提高经济发展 的速度。

\section{2. 狭义公式的启示意义}

第一, 应鼓励消费, 尽量提高消费倾向。但是, 必须将其控制在 $\beta<\frac{1}{1-t}$ 的范围内, 且必须注意 
消费结构。在第一、二、三产业的产品中, 对第一、第二产业的产品, 由于其大量消耗自然资源, 所以, 应尽量节约其消费, 并注重提高第一产业产品的质量以及第二产业产品的质量和寿命, 提高消费质量; 对于第三产业的产品, 由于其主要消耗可不断再生的人力资源, 故应大力鼓励其消费, 以大大提高人民 的生活质量。对于产业面而言, 应优化第一产业, 合理布局并优化第二产业, 大力发展第三产业。国家 应根据以上原则调整投资政策。第二, 合理制定税率, 将 $t$ 控制在 $1-\frac{1}{\beta} \leq t<1-\frac{\gamma}{\beta}$ 范围内, 并作适时调整。 第三, 合理控制进口倾向, 将其控制在 $0<\gamma<\beta(1-t)$ 范围内, 并实现进出口贸易基本平衡或有 一定的顺差, 但是, 经济均衡时的出口额必须大于自发性进口。第四, 将增长方式从外延式增长转变为 内涵式增长, 即在提高产品质量上下功夫, 提高产品平均质量水平, 增加国民收, 促进经济增长。

\section{6 年 3 月 4 日修改于自贡}

\section{参考文献 (References)}

[1] 新华网. 胡锦涛在中国共产党第十七次全国代表大会上的报告[R]. 2007. http://news.xinhuanet.com/newscenter/2007-10/24/content_6938568.ht

[2] 新华网. 习近平讲话新添 5 个动词阐释五大发展理念[R]. 2016. http://news.xinhuanet.com/politics/2016-01/08/c 128610376.htm

[3] 新浪网. 习近平如何向人大代表诠释五大发展理念[R]. 2016. http://news.sina.com.cn/2016-03-02/doc-ifxpvysv5116867.shtml

[4] 谭崇台. 发展经济学[M]. 上海: 上海人民出版社, 1989.

[5] 谭崇台. 发展经济学的新发展[M]. 武汉: 武汉大学出版社, 1999.

[6] 谭崇台. 发展经济学[M]. 太原: 山西经济出版社, 2001.

[7] 多恩布什, 费希尔, 斯塔兹. 宏观经济学[M]. 北京: 中国人民大学出版社, 2000.

[8] 高鸿业. 西方经济学 [M]. 第二版, 北京: 中国人民大学出版社, 2000.

[9] 斯蒂格利茨. 经济学(下册) [M]. 姚开建, 等, 译. 北京: 中国人民大学出版社, 1997. 